\title{
Dependability Evaluation and Supervision in Thermal Power Plants
}

\author{
Marwa Ben Hammouda, Mohamed Najeh Lakhoua, Lilia El Amraoui \\ U.R: Mechatronic Systems and Signals, ENI Carthage, University of Carthage, Tunisia
}

\begin{tabular}{l} 
Article Info \\
\hline Article history: \\
Received Apr 7, 2015 \\
Revised May 18, 2015 \\
Accepted Jun 2, 2015 \\
\hline Keyword: \\
Automated systems \\
Dependability \\
Functional analysis \\
Supervision \\
Thermal Power plants
\end{tabular}

Article Info

Article history:

Received Apr 7, 2015

Revised May 18, 2015

Keyword:

Automated systems

Dependability

Supervision

Thermal Power plants

\begin{abstract}
In order to improve the productivity and the consistency of its maintenance strategies, the industrial world is based on different techniques and tools developed to ensure safe operation and the supervision of production systems. In fact, dependability evaluation is crucial to controlling the risks associated with system failure, and for this reason, it is one of the fundamental steps in automated system design. In this paper, we present firstly the basic concepts for the study of dependability as well as functional systems analysis. Thus, we present the method SADT (Structured Analysis Design technique). Given the ineffectiveness of methods that are currently exploited are not appropriate because the level of complexity of such industrial systems, we propose in the first the Safe-SADT method which allows the explicit formalization of functional interaction, the identification of the characteristic values affecting complex system dependability, the quantification of RAMS parameters (Reliability, Availability, Maintainability, and Safety) for the system's operational architecture. Secondly, a methodology for designing supervisory production systems has been presented and has been applied on an example of a SCADA (supervisory control and data acquisition) system of a thermal power plant. Finally, a model of operating safety and supervision of a production system is proposed.
\end{abstract}

Copyright (C) 2015 Institute of Advanced Engineering and Science. All rights reserved.

\section{Corresponding Author:}

Marwa Ben Hamouda

U.R: Mechatronic Systems and Signals, ENICarthage,

University of Carthage, Tunisia.

Email: marwa.benhammouda@hotmail.com

\section{INTRODUCTION}

Today, the dependability of production systems is more and more complex to perform, not only because of the number of variables always more numerous to monitor but also because of the numerous interrelations existing between them, very difficult to interpret when the process is highly automated. Indeed, dependability characterizes the performance of a system in that reflects its ability to achieve its mission. It is connected to its capacity to resist the material, software and human failures, and the attacks of its environment [1].

The concepts of supervision are also essential. Infact, the supervision can detect anomalies without necessarily act directly on the system in order to optimize its operation and to ensure the safety [2].

In this paper, we present in a first part the main definitions and concepts of dependability. In the second part, we present the architecture and the characteristics of supervision. In the third part, we present the methods and tools ensuring the dependability analysis for products systems under design or redesign. Finally, we present a general model in order to study the dependability and the supervision for an example of an industrial installation and to have a safe industrial system, a supervision method was implemented. 


\section{DEPENDABILITY OF COMPLEX AUTOMATED SYSTEMS}

Dependability aims to establish trust between the client and the designer. This is why it is moving towards methodologies ensuring efficiency, accuracy and reliability. To achieve these objectives, functional analysis is a good way to design, evaluate and manage the dependability of complex automated systems.

The notion of industrial process covers a wide range of industrial sectors. Indeed, a system is defined as a set of interconnected elements, oriented towards achieving an objective.

Industrial systems are production tools that are subject to economic and technical constraints. They must be able to produce quality goods at high speeds required. They are also related to modern and efficient production techniques that require a high level of knowledge and skills. In fact, the complexity of industrial processes and the variety of conditions for their operations are steadily increasing. This is why these systems are often automated.

Researchers Cauffriez L. and al. [3] have presented a methodology for designing complex automated systems. This methodology is divided into six actigrammes (Figure 1). Indeed, actigrammes 1 and 2 concern the functional architecture, actigrammes 3 and 5 relate to the hardware architecture and actigrammes 4 and 6 concern the operational architecture.

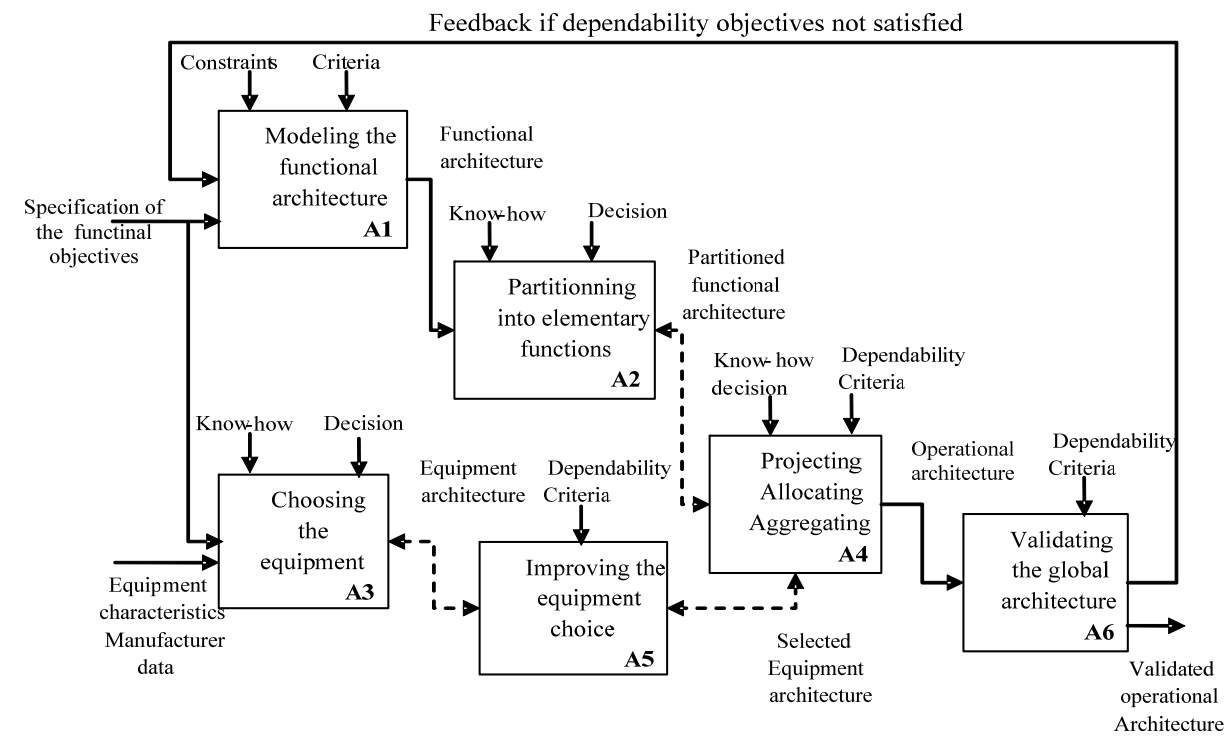

Figure 1. A methodology for the design of intelligent distributed controlled system [3]

\subsection{Dependability Concepts}

Dependability is understanding, assessing, predicting, measuring and control failures of technological systems and human failures [4]. Dependability plays an important role in industrial systems. Indeed, it is the science of failure and is characterized by the ability of an entity to satisfy one or more of the vital system functions under given conditions. Four interdependent parameters define the RAMS: Reliability, Availability, Maintainability and Safety.

\subsubsection{Reliability}

According to NF EN 13306, reliability of a system is the ability for it to perform its function under given conditions during a given time interval [5]. The term reliability is also used to determine the system/equipment concerned, a guaranteed operating time before the occurrence of a failure. Consider the time $\mathrm{T}$ of occurrence of the failure; this random variable to define the concept of reliability that is interpreted as the probability that the entity do not crash after a given time t for given conditions. Reliability is then defined as the probability associated $\mathrm{R}(\mathrm{t})$ to this notion. It is defined by:

$\mathrm{R}(\mathrm{t})=$ probability of a non-defaulting entity on the interval $[0, \mathrm{t}]$, assuming it is not in default at time $\mathrm{t}=0$ 


\subsubsection{Availability}

Availability, rated A (t) is the ability of a component or system to be up and running at a given time. More specifically, availability is the ability to respond to the request in time. The AFNOR X 60-500 defines availability as "the ability of an entity to be able to accomplish a required function under given condition at a given time or during a given time interval, assuming the providing the support needed maintenance is assured "[6].

The term availability is then defined as a probability that an entity may determine, based on the reliability of the results, the quality of service provided by the system / equipment, under given conditions at a given time. The probability associated with A (t) at time $\mathrm{t}$ is also referred to availability and is expressed by:

$$
A(t)=P(\text { no-defaulting } E \text { at time } t)
$$

\subsubsection{Maintainability}

Maintainability M (t) is the ability of a component or system to be maintained or restored condition. Next AFNOR standard is: " under the given conditions of use, the ability of an entity to be maintained or restored in a given time interval, in a state in which it can perform a required function when the maintenance is performed under given conditions with prescribed procedures and resources "[7].

Maintainability of a serviceable entity is characterized by a probability $\mathrm{M}(\mathrm{t})$ the maintenance of an entity $\mathrm{E}$ completed in given conditions, with procedures and prescribed means, is completed at time $\mathrm{t}$, given that $\mathrm{E}$ fails to time $\mathrm{t}=0$ [2]. This can be expressed by: $\mathrm{M}(\mathrm{t})=\mathrm{P}(\mathrm{E}$ maintenance was completed at time $\mathrm{t})$.

\subsubsection{Safety (Security)}

Security is the ability of a product to meet during all phases of life, an acceptable level of safety hazards likely to cause staff assault or a major degradation of the product or its environment. Security is "the ability of an entity to avoid appearing in given conditions, critical or catastrophic events» [7]. The role of a specialist SdF is to reduce the business risk to its acceptable level by defining: the risk acceptability criteria, security design methods and residual risk assessment methods and verification levels accessibility.

\subsection{Methodology for Designing Complex Systems}

To study the dependability of complex automated systems, several methods based on static and dynamic modeling have been put in place. Indeed, functional analysis is based primarily on the needs analysis, functional analysis necessary technical and functional analysis. Features such as a high degree of data output trustworthiness, service availability, and protection are the result of a high degree of service dependability which is a very important property in the cloud computing environment. Thus it highlights some methods, usually based on a graphical representation, in order to facilitate the understanding of complex automated systems and the study of their dependability [8].

\subsubsection{Presentation of the SADT Method}

The SADT method is a method of design and analysis of complex systems. It was developed by DT Ross in the Softech company in the United States around 1974 [9]. It is a method of descending functional analysis that starts from the general to the particular [10]. Indeed, technical system can be described by a SADT model represented by a diagram assembly (actigramme and datagram) hierarchically ordered. The methodology is rigorous, with specific schema syntax rules that allow a SADT model to communicate concisely and precisely important information on the operation and the external interfaces of the system [11].

Processors or mechanisms are natural and technological elements that perform the function which is characterized primarily by an action on the inputs. The entry consists of the incoming prime matter. It is modified by the function and can be considered: product (material), energy or information. The output shows the outgoing prime material that is mainly working materials provided with its added value. One can find with this outgoing prime material for reports, energy losses and waste. Controls or constraints or steering control are the parameters that trigger or modify the realization of a function. They are classified into four categories: the configuration parameters; tuning parameters; operating data / operating value; setting energy or presence of prime matter.

\subsubsection{Presentation of Safe-SADT Method}

Methods for assessing the dependability currently operating are not appropriate, given the level the complexity of industrial systems. Inefficient Existing methods have led to the development and propose the Safe- SADT method [12], [13], [14]. This method allows the explicit formalization of functional interactions, identification of characteristic values that affect the dependability of complex systems, quantification of 
parameters RAMS (Reliability, Availability, Maintainability and Safety) of the operating system architecture, and operational validation of this architecture in terms of dependability objectives and constraints set in the functional specification [14]. The main purpose of this method is to evaluate the dependability parameters of a global system during the design phase taking into account its evolution in time (Figure 2).

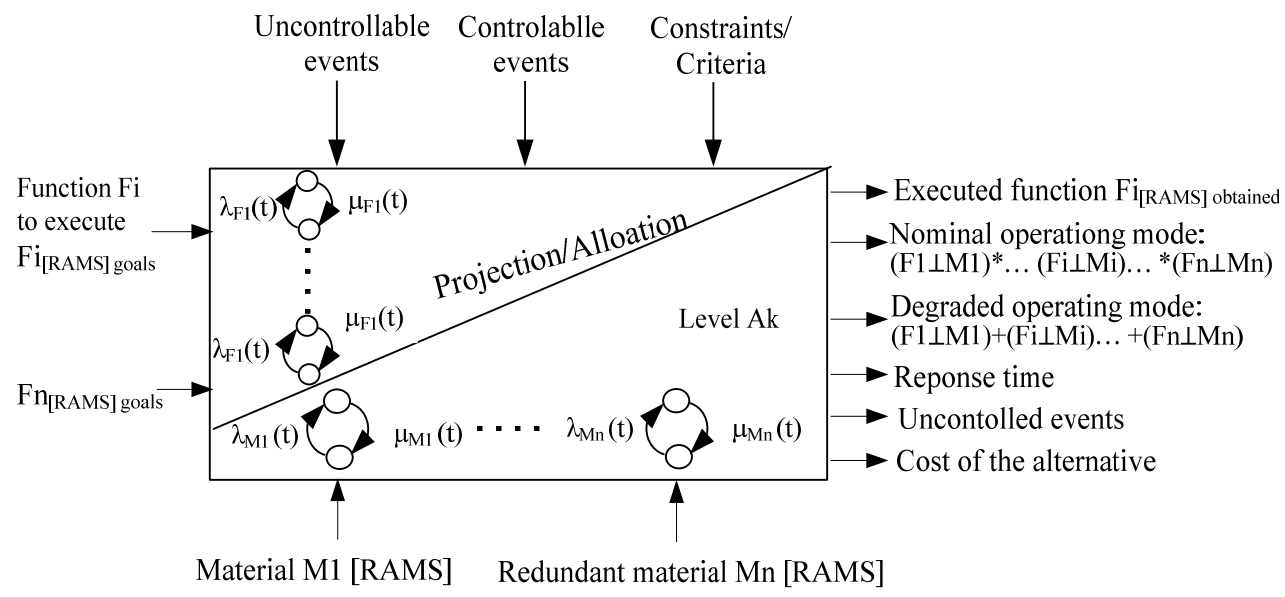

Figure 2. SAFE-SADT formalism

To meet the objectives specified in a specification, the Safe-SADT method defined the operational architecture of a system that is obtained from the projection of a functional architecture on a set of resources. Given that any function performed by software embedded in the material is defined by a structured series, the reliability must be advanced across the system [12]. A Safe-SADT block is to the specification of the reliability target for studying the functions and quantification of RAMS parameters of functions.

The input for the Safe- SADT block contains the different functions that the system can run (speed control, temperature control, etc.). The objective defined reliabilities for these services are often indicated in the specifications of the functional requirements and RAMS parameter vector association.

The output for Safe-SADT block shows the evolution of the RAMS parameters of functions performed, the results obtained by the projection / desired allocation, as well as the response time and controllable and uncontrollable events. The Safe-SADT formalism allows the designer to define, for each subsystem at each hierarchical level, some parameters that will be aggregated to determine the value resulting from the global setting sub- system functions or modes of operation. The response times and costs are convenient to evaluate. The response time of each sub- system depends on the technology and operating system [13].

At the top of the Safe-SADT block, there are non-controllable events such as random hardware failures or software and controllable events such corrective actions, which bring the system to a working condition. Constraints and criteria (eg, reliability, characterization systems for performance, subsystems) are also considered with the controls on top of a Safe- SADT block.

At the bottom of the block, the equipment and their dependability characteristics are known from the experimental results, laboratory test or manufacturer data. The formalism used to model the redundancy execution medium to study the impact of redundancy on RAMS parameters [12].

The use of Top-Down approach for the decomposition of the system, starting in global level A0 until the elementary functions of level An. This approach allows the explicit modeling of the characteristics of the operational architecture and identification of its dependencies in order to better understand the dependability of the overall architecture. Once the lowest level of the Safe- SADT block is reached, it is possible to assess the RAMS parameters of the system using the BOTTOM-UP approach. During this stage of aggregation, designers can verify that the specifications and constraints imposed by the entire system are satisfied. The designer can also at this stage to quantify the response time and estimate the cost of alternatives for the operational architecture. 


\section{THE INDUSTRIAL SUPERVISION}

Supervision consists of commanding a process and supervising its working [15], [16]. To achieve this goal, the supervisory system of a process must collect, supervise and record important sources of data linked to the process, to detect the possible loss of functions and alert the human operator. In addition, the supervision of industrial processes allows the control and the command of automated process in order to optimize its operation and to ensure to security. The main parts of a supervised system are [17], [18], [19]:

- The Man-Machine Interfaces (MMI), displaying information thanks to the information synthesis system.

- The supervisory tools, supplying services thanks to the automatic supervisory system and the decision support systems.

- $\quad$ The control/command part, interface between the MMI, the supervisory tools and the process.

- The process is also called production system or operative part, performing the physical work on the input product flow.

These tasks are performed by human operators who make decisions after evaluating the situation of the process from the observed variables, using expert knowledge to solve complex situations [20], [21].

Supervisory control and data acquisition systems (SCADA) are widely used in industry for supervisory control and data acquisition of industrial processes. The process can be industrial, infrastructure or facility [15-16]. SCADA system is used to observe and supervise the shop floor equipments in various industrial automation applications [17-18]. A SCADA system is used to monitor and supervise an overall process being implemented by individual automated systems. It typically consists of the following four items [22], [23], [24]:

- A master terminal unit (MTU), which is the central server where information about the overall process is collected. This allows a centralized workstation operator to monitor, analyze, and control the entire process from a remote location.

- $\quad$ PLCs and/or RTUs, which control the field equipment doing the process.

- Communications equipment for transferring data between the PLCs/RTUs and the MTU.

- Human machine interface (HMI) software, which enables the on-screen operation of the inputs (without physically touching them) and displays the status of the outputs. The HMI is installed on all workstations (including the MTU), allowing the operators to have easy and intuitive control over the systems.

\section{PROPOSAL FOR DEPENDABILITY MODEL AND SUPERVISION}

The development of a model helps us to facilitate the analysis, description and understanding of the industrial system [25]. Formalism, concepts and representation tools that we will use will help to deepen the study system in the design stage. Our goal is the rigorous use of a methodological approach to functional analysis and supervision of an industrial facility. This methodology will be adopted to analyze production systems to provide a tool for communication between the various users of the system. We quote as an example, thermal power generation of electrical energy.

Figure 3 shows the three essential phases that are central to the development of the model: functional analysis of the system; analysis of the operational architecture; supervision of the industrial plan. 


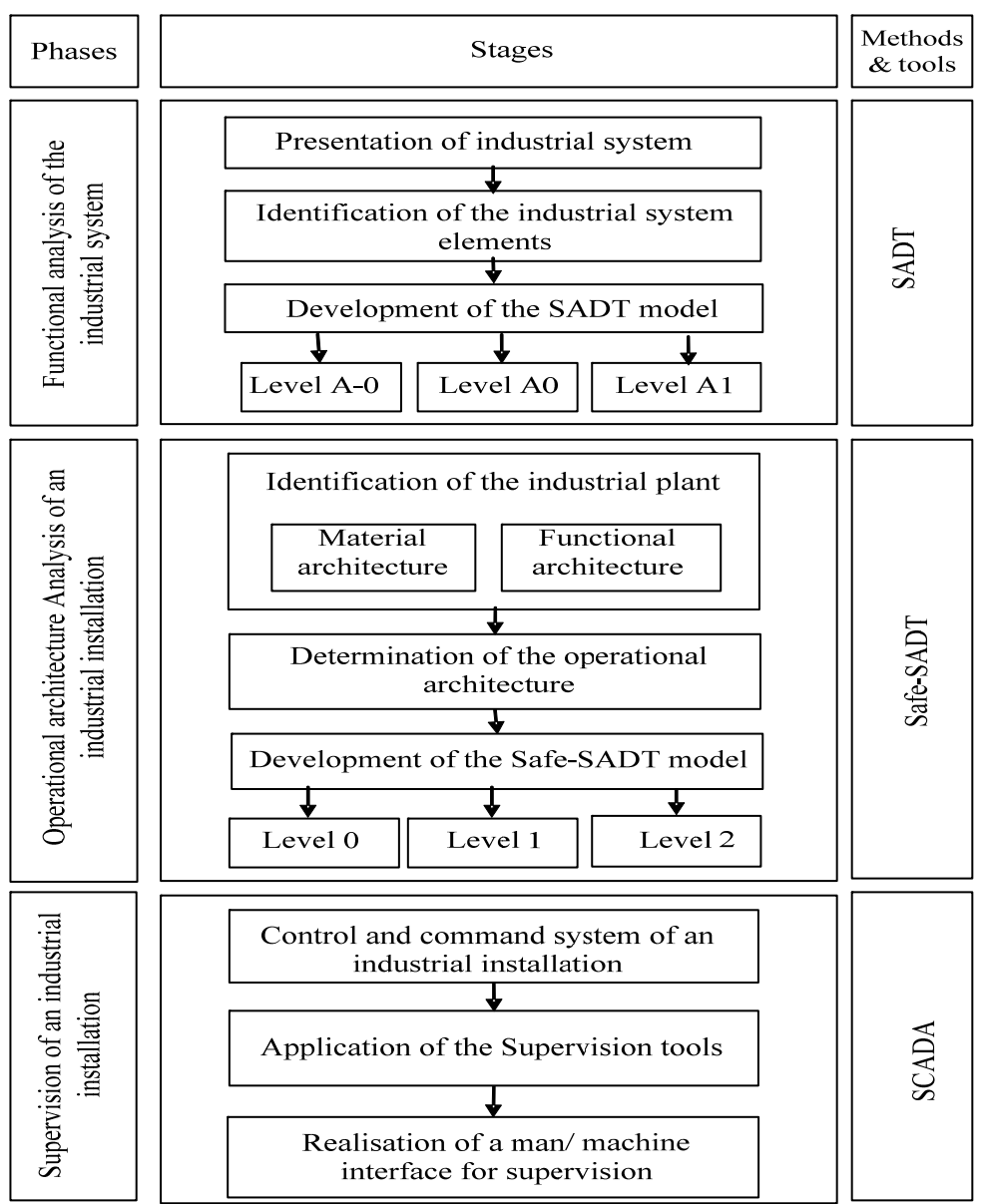

Figure 3. Model of analysis and supervision of an industrial process

In the first phase, we proceed with an analysis and functional modeling of the industrial system based on the SADT method. The structure of this method to master the complexity of the process with its top-down and modular analysis.

In the first place, we prepare a SADT model to define the objectives and the view for which the model is created. Then we create the A-0 diagram representing the main function for analysis in an actigramme. The digraph A0 and A1 development is the third step in this phase.

This analysis allows us to obtain a functional architecture and hardware architecture of the system. An example of modeling of a thermal power plant of electric power is underway.

Once the functional architecture and hardware architecture have been identified, the next step is to determine the operational architecture of an industrial process using the new Safe- SADT formalism.

The first step of such a functional analysis approach by Safe- SADT method is to identify the system and the functions to be performed and the materials used media. Then the second step is to define the operational architecture by the projection (allocation) of the functional architecture of the hardware architecture. Finally, we proceed with the development of Safe- SADT model. When we are faced with a SADT Safe- block complex, we use the same decomposition process of the SADT method. The bottom-up approach is then used to aggregate the resulting basic functions of the previous decomposition.

This second phase of the model provides an operational architecture of the industrial plant studied. An example of a water station of a thermal power plant for producing electric energy has been chosen in order to validate this second phase.

After the two phases of analysis of the functional and operational architecture of the system, the third phase of the model is to implement a monitoring tool as well as man-machine interfaces for monitoring industrial process. Indeed, supervision allows monitoring and control of operation of an installation in order to stay within the normal operating range regardless of external disturbances. Using a SCADA system (SCADA) for example, all anomalies identified in a water station of a thermal power plant can be detected in 
real time, from alarms and can identify their causes.Thus supervision is a reference tool for the operator and it also allows him to interact directly with a control and supervision system.

\section{STUDY OF DEPENDABILITY AND SUPERVISION OF REVERSE OSMOSIS STATION}

The Production Centre Rades Electricity is a thermal power plant (TPP) that consists on a system producing the electricity while using dry water steam to drag the alternator in rotation (Figure 4). This steam is generated in a furnace that transforms the chemical energy of the fuel (natural gas, heavy fuel-oil) in calorific energy.

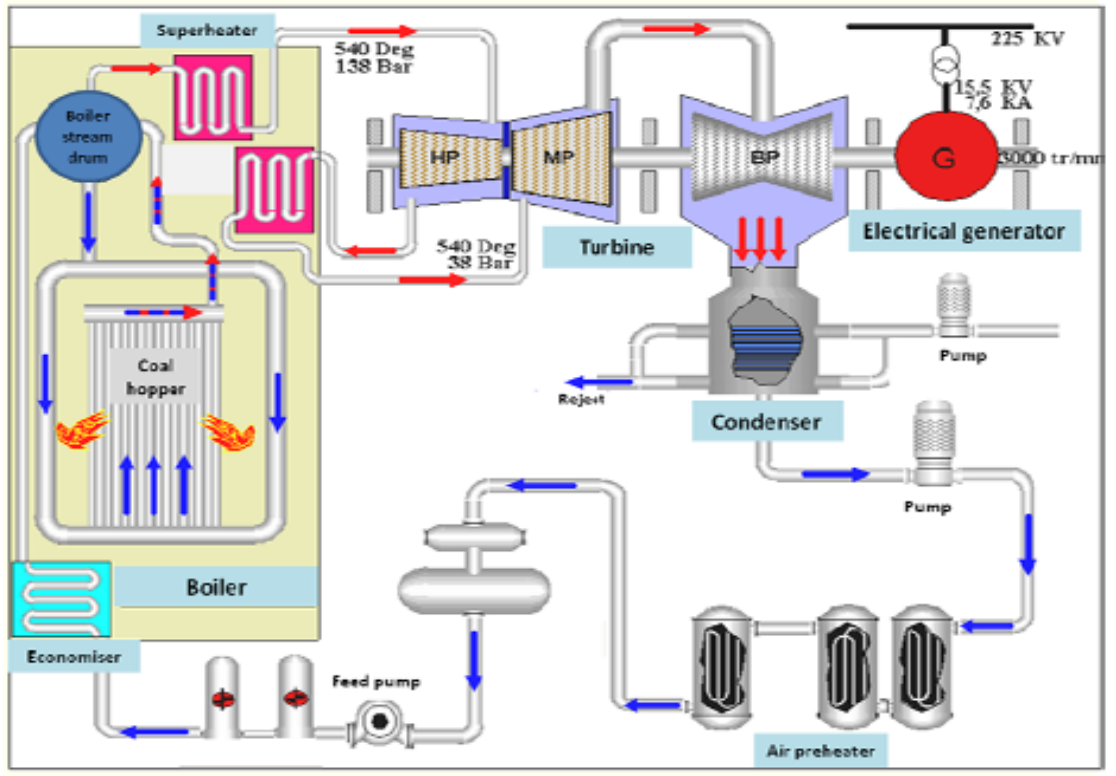

Figure 4. Functionality of a thermal power plant

This is one of the most important productions of electric power stations in Tunisia (37\% of national production). In fact, a TPP is a power plant in which the prime mover is steam driven. Water is heated, turns into steam and spins a steam turbine which drives an electrical generator. After it passes through the turbine, the steam is condensed in a condenser. The greatest variation in the design of TPPs is due to the different fuel sources. Some prefer to use the term energy center because such facilities convert forms of heat energy into electrical energy [26].

In TPPs, mechanical power is produced by a heat engine which transforms thermal energy, often from combustion of a fuel, into rotational energy. Most thermal power plants produce steam, and these are sometimes called steam power plants. TIPs are classified by the type of fuel and the type of prime mover installed [26].

\subsection{Presentation of the Studied System}

The reverse osmosis (R.O) station operates on the reverse osmosis phenomenon, which consists of the spontaneous diffusion of a chemical compound (water) through a semi permeable membrane. It occurs when a substance is presented at different concentrations from one side and the other of the membrane. This difference causes excess pressure called osmotic pressure. The distribution of this compound is done so that the two levels on one side and the other of the membrane tend to equalize. In contrast, reverse osmosis enhances concentration of the more concentrated solution by subjecting the less concentrated solution to a pressure greater than the osmotic pressure (Figure 5). 


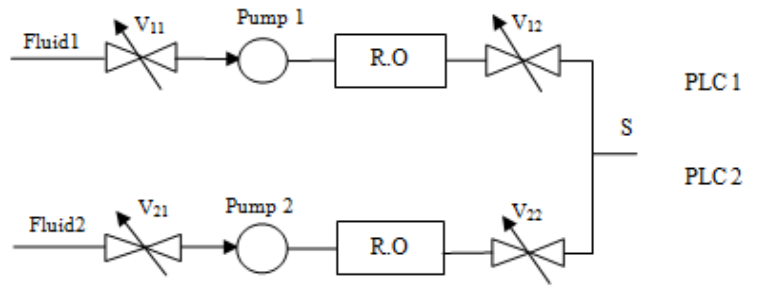

Figure 5. The reverse osmosis station

To offer a general description of the reverse osmosis process, we present knot A-0 SADT model (Figure 6). Indeed, among the elements of the reverse osmosis station, we can mention: filter membrane, pump. The SADT method is essentially a structured method of representation designed from simple concepts. It allows considering the process as a structure composed of simpler systems interact. The hierarchical structure diagrams used to represent various levels of detail and in a relatively concise, to the complex simple systems. We used the software BpWin for representing diagrams SADT model.

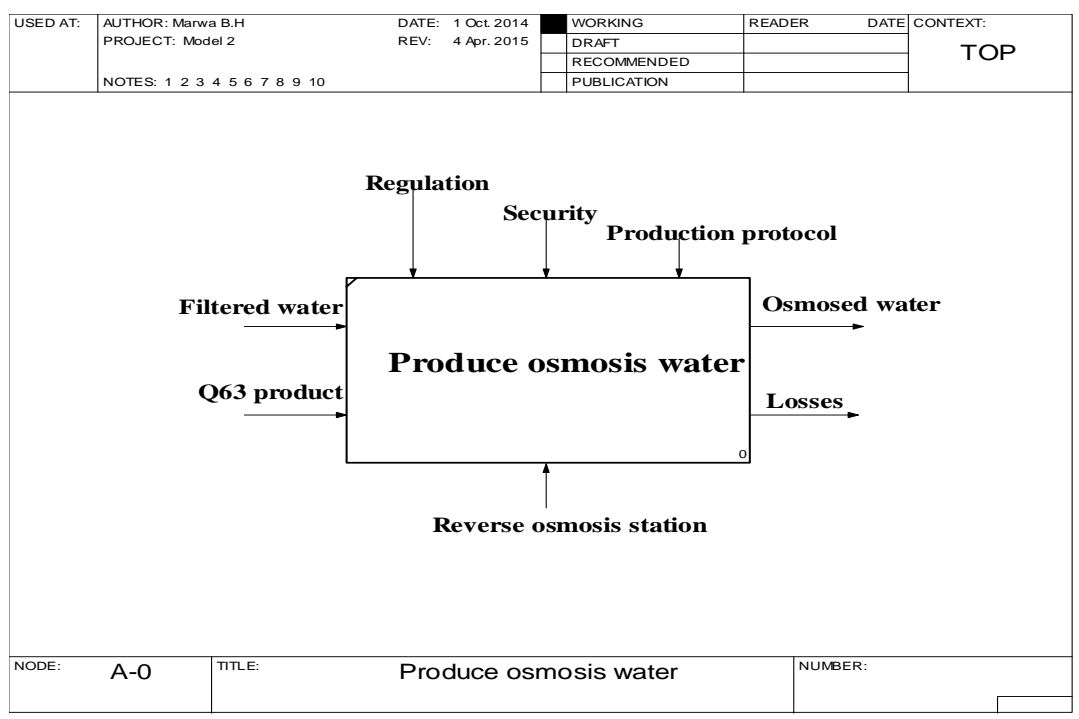

Figure 6. A-0 level of SADT model of a reverse osmosis station

\subsection{Validation of the Proposed Model}

To validate the first phase of our general model of analysis and supervision of an industrial process, we used the SADT method is a general method that seeks to foster communication between applicants and users on the one hand and designers and directors, on the other. After modeling the electricity production process TPP the SADT method, using actigrammes of SADT, we established levels A-0, A0 and A1 SADT model presented by the three figures 7 and 8 .

\subsubsection{Application of SADT Method}

The figure below shows a SADT method by thermal power plant. The activity diagram (actigramme) developed helped to create or generate a given output (electric energy, losses), to transform, or modify or change state an input data (fuel, air, water) and seek the input data from control guidelines, based on the potential mechanisms ( boiler, turbine and generator). 


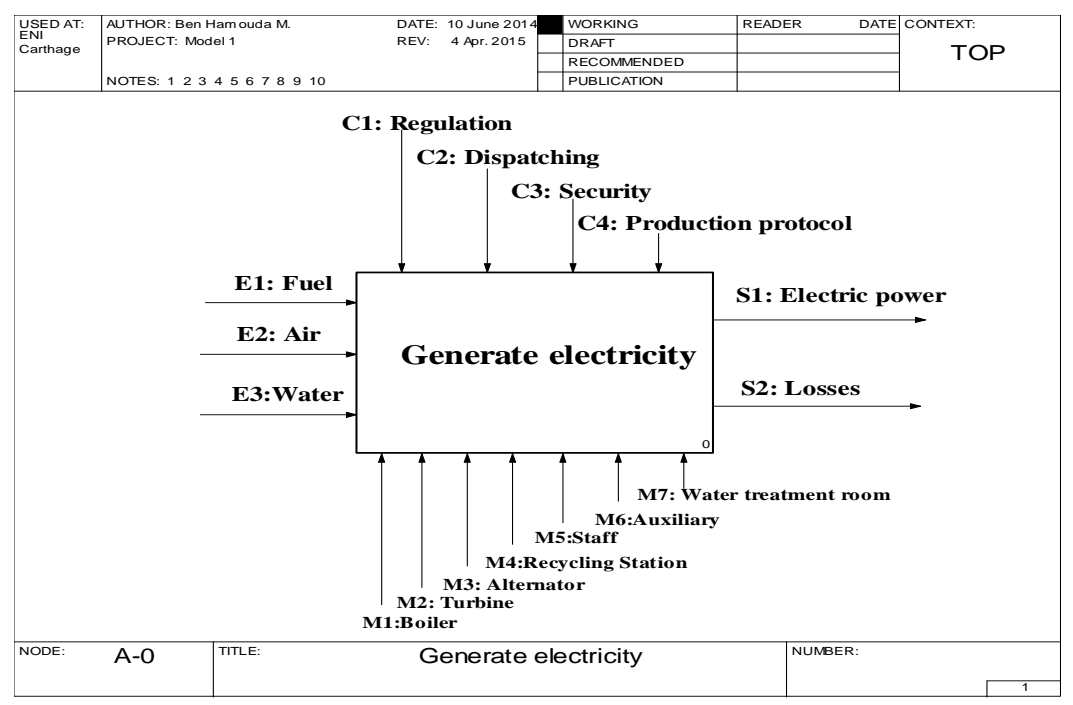

Figure 7. A-0 level SADT model of a thermal power plant

The goal of the obtained model SADT is multiple: the model SADT will allow to take offence at the state of the studied system, as shows it both presented levels, and to clear the complexity of the system.

Indeed, among the complex activities in the TPP, we can quote: the preparation of the water; the production of the calorific energy; the production of the mechanical energy; the production of electrical energy; recycling steam.

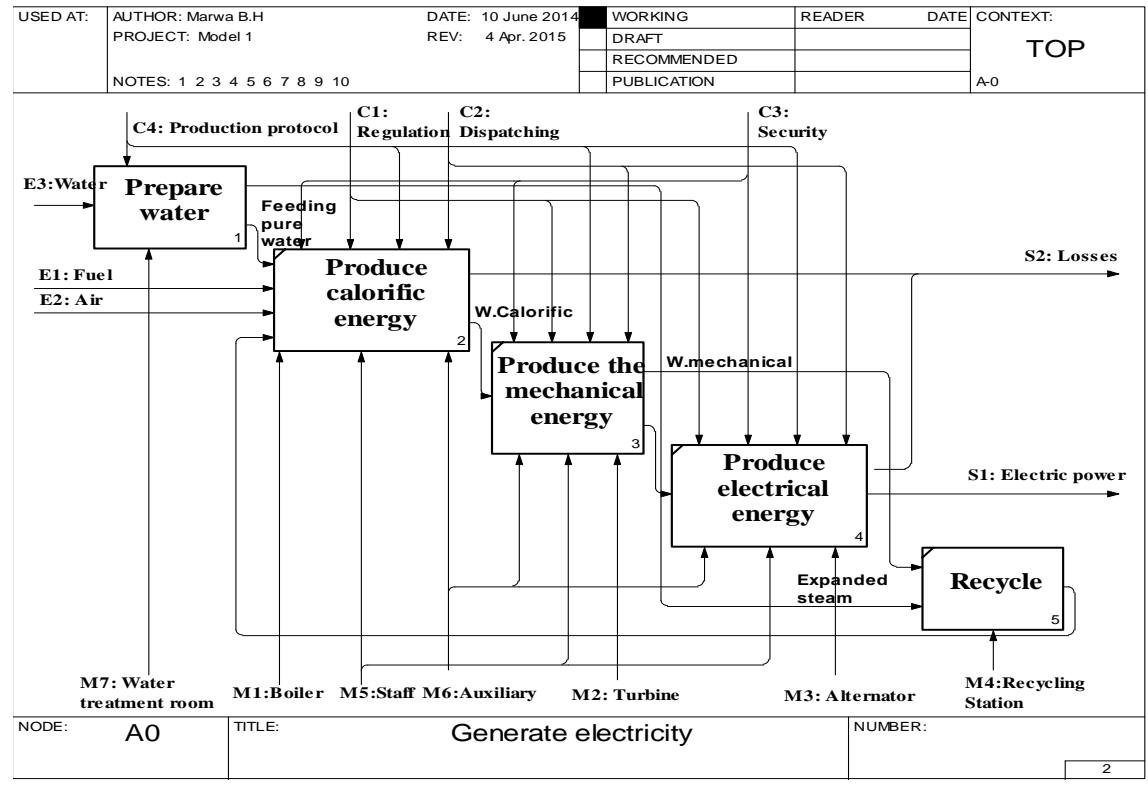

Figure 8. A0 level of SADT model of a thermal power plant

\subsubsection{Application of Safe-SADT Method}

In this section, we present the overview of the Safe-SADT model of the system hydraulic part of the reverse osmosis station. This system shows that the representation with Safe- SADT method is more reliable than the SADT method because it takes the parameters of dependability and the various operating modes (figure 10).

The organization and behavior of functions describe the activities of the automation system throughout its life cycle. In our example, we can define the functions of our system as follows:

“Open valve Vij”, “close valve Vij” and “control pump Pi” 
“Open valve Vij”, “close valve Vij” and “control pump Pi”

The first architecture to be defined in the system design is the functional architecture. The functional design phase is to decompose the main functions of the system into simpler functions (Table1). These functions are also broken down into even simpler sub-functions.

Table1. Functional Architecture

\begin{tabular}{l}
\hline Functional Architecture \\
\hline Open valve $\mathrm{V}_{11}$, Close valve $\mathrm{V}_{11}$ \\
Open valve $\mathrm{V}_{21}$, Close valve $\mathrm{V}_{21}$ \\
Open valve $\mathrm{V}_{12}$, Close valve $\mathrm{V}_{12}$ \\
Open valve $\mathrm{V}_{22}$, Close valve $\mathrm{V}_{22}$ \\
Control pump $\mathrm{P}_{1}$ \\
Control pump $\mathrm{P}_{2}$
\end{tabular}

Table 2. Material Architecture

\begin{tabular}{c}
\hline Material Architecture \\
\hline $\mathrm{V}_{11}+\mathrm{PLC}_{1}$ \\
$\mathrm{~V}_{21}+\mathrm{PLC}_{2}$ \\
$\mathrm{~V}_{12}+\mathrm{PLC}_{1}$ \\
$\mathrm{~V}_{22}+\mathrm{PLC}_{2}$ \\
$\mathrm{P}_{1}+\mathrm{PLC}_{1}$ \\
$\mathrm{P}_{2}+\mathrm{PLC}_{2}$ \\
\hline
\end{tabular}

Carrying out the functions of the functional architecture requires a choice of equipment (hardware and software), which is the hardware architecture. The hardware architecture also specifies for each equipment all of its global characteristics (Table 2). The hardware architecture of our system consists of: valves, pumps and industrial programmable logic controllers (PLC).

The operational architecture is the projection of the functional architecture of the hardware architecture. This projection leads to assign functions to equipment that uses the cost function to evaluate different solutions, and uses assessment tools such as those used to assess a level of dependability or performance level.

Table 3. Operational Architecture

\begin{tabular}{lcl}
\hline & Operational Architecture & \\
\hline Open $\mathrm{V}_{11}$ & $\mathrm{~V}_{11}$ & $\mathrm{PLC}_{1}$ \\
Close $\mathrm{V}_{11}$ & & \\
Open $\mathrm{V}_{21}$ & $\mathrm{~V}_{21}$ & $\mathrm{PLC}_{2}$ \\
Close $\mathrm{V}_{21}$ & & \\
Open $\mathrm{V}_{12}$ & $\mathrm{~V}_{12}$ & PLC $_{1}$ \\
Close $\mathrm{V}_{12}$ & & \\
Open $\mathrm{V}_{22}$ & $\mathrm{~V}_{22}$ & $\mathrm{PLC}_{2}$ \\
Close $\mathrm{V}_{22}$ & $\mathrm{P}_{2}$ & $\mathrm{PLC}_{2}$ \\
Control $\mathrm{P}_{2}$ & $\mathrm{P}_{3}$ & PLC $_{1}$ \\
Control $\mathrm{P}_{2}$ & & \\
\hline
\end{tabular}

Figure 9 shows the development of Safe-SADT model of the hydraulic system. This method implemented the steps that detail how the system and its functional architecture, physical and operational. The analysis by the Safe-SADT method provides good data carrier on RAMS parameters components in order to determine those of the general system. 


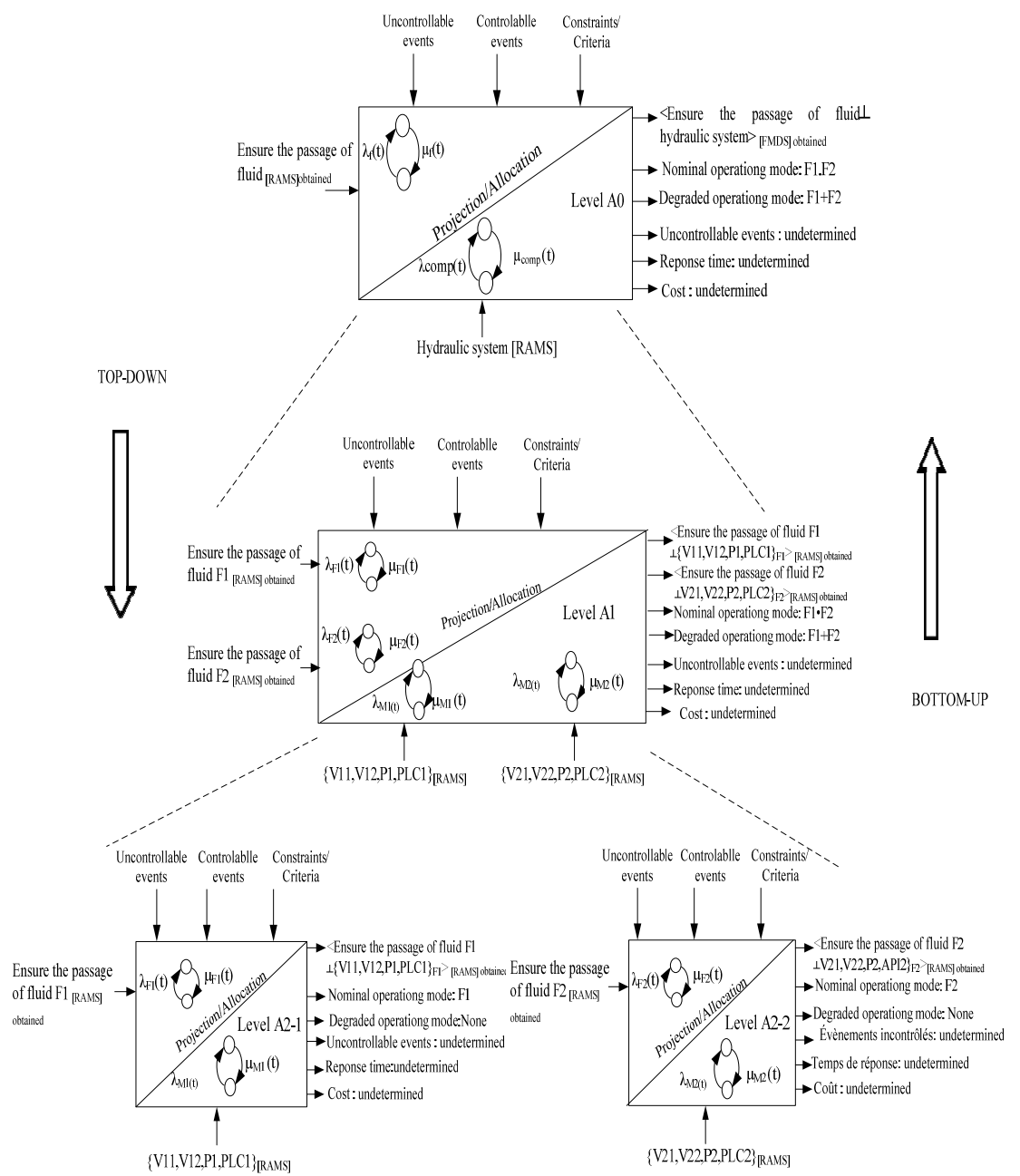

Figure 9. Development of Safe-SADT model of the hydraulic system

\subsubsection{Supervision of the Raw Water Tank Level}

Supervision plays an important role in the safety of operators and the environment to ensure the proper functioning of the system. She considered a tool to ensure the dependability of an industrial process. We present in this section a study of a water treatment applied by reverse osmosis and the steps required for configuration of the signals. Thus he must follow certain steps in order to monitor the operation of the facility. In this section, we present the different configuration on the ICC software (Integrated Control Configuration): Software to create and configure programs residing in the CP60 (Process Control).

An example of supervision of the raw water tank level by a SCADA system of a TPP is presented (Figure 10). The unit is powered by two water tanks. Each tank $2300 \mathrm{~m}^{3}$ of water. The water level will be displayed on the SCADA system by percentage (\%) and has as a unique identifier (12GA1LX001).

The stations belong to a superior network Ethernet $(10 \mathrm{Mb} / \mathrm{s})$. Principally, this network enables to exchange files between the stations. It enables to avoid the overload of the Node bus network. In fact, the SCADA system is composed by modules that exchange information thanks to the communication network.

SCADA receives the information displayed on the screen and device status if they move from normal to abnormal with the colors. In the SCADA system, there are three levels:

Data Acquisition; Data Treatment and Men / machine Interface.

I/A: Intelligent / Automation; FBM: Field bus modules; FCM: Field Bus Communication Module; AW: Application work station; WP: Work station Processor; CP60: Control Process60 and DNBT: Dual Node Bus.

FoxDraw is a graphical configurator used to build I/A series process graphics to be displayed via FoxView software. It allows creating and maintaining dynamically updating process displays. Displays can represent the plant, a process area, or a detailed portion of the process. 
FoxDraw provides numerous time and effort saving features to make building, configuring, and maintaining displays easy. Included with FoxDraw is a large library of graphical components ready to be included and configured in displays. FoxDraw includes over 1200 prebuilt objects such as pumps, tanks, pipes, motors, valves, and ISA symbols.

The different stages of this application are the following:

- $\quad$ Choice of the site of the signal (FBM module).

- $\quad$ Programming of the AIN block (Analogical Input) for the supervision of the raw water tank level signal.

- $\quad$ Programming of the CIN block (digital Input) for the supervision of the signal conductivity ball furnace.

- Test by injection of current for standardization of the AIN block and test of the alarm by short circuit for the CIN entrance.

- $\quad$ Passage of the cable between the room of sampling and the SCADA room.

- Branching of the analogical signal and the numeric signal.

- Creation of a new tabular for the general vision of the room of sampling of the TPP.

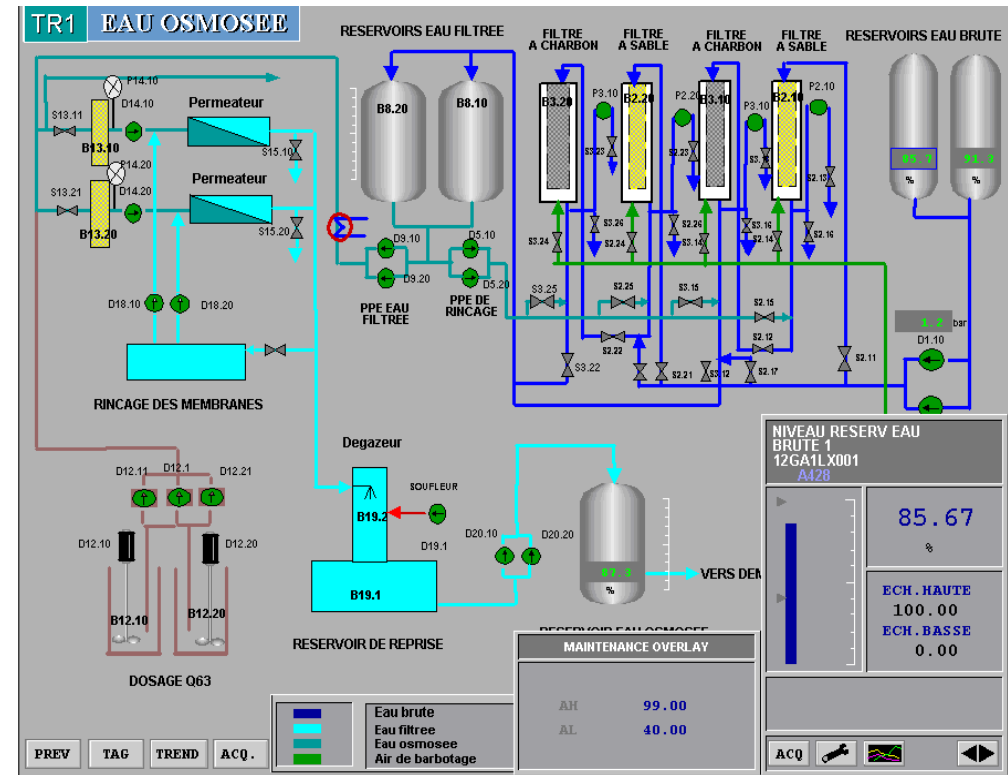

Figure 10. The Final alarm display

\section{CONCLUSION}

The development of information technology tools and automation systems involves the basic concepts of operation and safety supervision. Indeed, functional analysis and structured SADT method was used and a new version of this method that takes into account the dependability parameters Safe-SADT has been studied. To propose a functional modeling, a general methodological approach and supervision, a security analysis model of operation and supervision of an industrial system was developed. Thus we propose a validation of the proposed methodology for an example of an industrial installation with a thermal power plant of electric power. To have a safe industrial system, a supervision method was implemented.

We are considering taking into account other aspects in the analysis by the Safe-SADT method such as qualitative and quantitative aspects. Thus it is necessary to adopt simulation techniques using the Monte Carlo algorithm, for example, to optimize the various solutions adopted by increasing the number of functional and physical entities of the system studied.

\section{REFERENCES}

[1] Eugen I.G., Laura C., Helga M.S., "Dependability Analysis of PLC I/O Systems Used in Critical Industrial Applications”, V.E. Balas et al. (Eds.), New Concepts and Applications in Soft Computing, Studies in Computational Intelligence 417, pp. 201-217, 2013.

[2] Millot P., “Supervision des procédés automatisés et ergonomie”, Paris, France, Hermès, 1988. 
[3] Cauffriez L., Benard V.et Renaux D., "A new formalism for designing and specifying RAMS parameters for complex distributed control systems: the Safe-SADT formalism”. IEEE Transactions on Reliability, Vol.55. N³, pp. 397-410, 2006.

[4] Zwingelstein G., "Sûreté de fonctionnement des systèmes industriels complexes-analyse prévisionnelle et bases de données de fiabilité”. Techniques de l’Ingénieur S825, 2009.

[5] Villemeur A., "Sûreté de fonctionnement des systèmes industriels fiabilité, facteur humain, information". Collection de la Direction des études et recherches d’électricité de France, Paris, Eyrolles, 1988.

[6] Benard V., "Evaluation de la sûreté de fonctionnement des systèmes complexes, basés sur un modèle fonctionnel dynamique: la méthode Safe-SADT”. Thèse de Doctorat, LAMIH, UVHC, 2004.

[7] Mohammed A. AlZain, Ben Soh and Eric Pardede, "TMR-MCDB: Enhancing Security in a Multi-cloud Model through Improvement of Service Dependability”. International Journal of Cloud Computing and Services Science (IJ-CLOSER) Vol.3, No.3, pp. 133 144, June 2014.

[8] Ben Hamouda M., Lakhoua M.N., "Methodology of Operating Safety and Supervision of a Production System", CISTEM, IEEE, 3-6 Nov. 2014, Tunisia.

[9] Baldwin J.L., Werbos A.et Zaccheo S., "Augmenting SADT with UML: a hybrid approach for the design of operational science algorithm”, 2011.

[10] Lakhoua M.N., "Systemic analysis of a supervisory control and data acquisition system”, Journal of Electrical Engineering (www.jee.ro), vol.11, $\mathrm{N}^{\circ} 1,2011$.

[11] Lakhoua M.N., “Using Systemic Methods for Designing Automated Systems”, International Journal of Applied Systemic Studies, Inderscience, Vol. 2, No4, 2009, pp. 305-318.

[12] Lakhoua M.N., “Application of Functional Analysis on a SCADA system of a Thermal Power Plant”, Advances in Electrical and Computer Engineering journal, 9(2), 2009.

[13] Benard V., L. Cauffriez, D. Renaux, "The Safe-SADT method for aiding designers to choose and improve dependable architectures for complex automated systems” Reliability Engineering and System Safety, 2006.

[14] Cauffriez L., Renaux D., Bonte T.et Cocquebert E., "Systemic modeling of integrated systems for decision making early on in the design process”. Cybernetic and Systems: An International Journal, 44:1-22, 2013.

[15] Chee-Wooi T., Chen-Ching L., Manimaran, G., "Vulnerability Assessment of Cybersecurity for SCADA Systems", IEEE Transactions on Power Systems, Vol.23, Issue 4, Nov. 2008, p.1836-1846.

[16] Aydogmus Z., "Implementation of a fuzzy-based level control using SCADA, Expert Systems with Applications", 2008.

[17] Chartres J., “Supervision: outil de mesure de la production”. Techniques de l’Ingénieur R7630, 1997

[18] Racoceanu D., "Contribution à la surveillance des systèmes de production en utilisant les techniques de l'intelligence artificielle”. Thèse d'Habilitation, Université de Franche-Comté de Besançon, 2006

[19] Warcuse J., Menz B., Payne J.R., “Servers in SCADA applications”, IEEE Trans. Ind. Appl. 9 -2, 1997, p.12951334.

[20] Kusiak A., Zheng H., Song Z., “Models for monitoring wind farm power”, Renewable Energy 34, 2009, p.583-590.

[21] Guillermo F., Nourredine B., Terry M. and Curtis N., "Portable SCADA Security Toolkits”. International Journal of Information \& Network Security (IJINS) Vol.1 No.4, pp. 265 274, October 2012.

[22] Lakhoua M.N., "Surveillance of pumps vibrations using a SCADA", Control Engineering and Applied Informatics, vol.12, N¹, 2010

[23] Géza H., Csaba S., Hideki H., "Application of reconfigurable hardware technology in the development and implementation of building automation systems”, Environnemental engineering and management journal, 2014, 13(11): 2899-2905.

[24] Basseville, M. et M-O. Cordier, "Surveillance et diagnostic de systèmes dynamiques: approche complémentaire du traitement de signal et de l'intelligence artificielle”, Rapport INRIA, N²861, 1996.

[25] Ben Hamouda, "Sur la sûreté de fonctionnement et la supervision des systèmes industriels", Mastère Recherche ARTI, ENICarthage, Juin 2014.

[26] Prisyazhniuk V.A., “Alternative trends in development of thermal power plants”, Applied Thermal Engineering 28, 2008, pp.190-194. 